\title{
Cyclones causing wind storms in the Mediterranean: characteristics, trends and links to large-scale patterns
}

\author{
K. M. Nissen ${ }^{1}$, G. C. Leckebusch ${ }^{1}$, J. G. Pinto ${ }^{2}$, D. Renggli ${ }^{1}$, S. Ulbrich ${ }^{2}$, and U. Ulbrich ${ }^{1}$ \\ ${ }^{1}$ Institute for Meteorology, Freie Universität Berlin, Berlin, Germany \\ ${ }^{2}$ Institute for Geophysics and Meteorology, University of Cologne, Cologne, Germany
}

Received: 14 January 2010 - Revised: 15 April 2010 - Accepted: 21 May 2010 - Published: 1 July 2010

\begin{abstract}
A climatology of cyclones with a focus on their relation to wind storm tracks in the Mediterranean region (MR) is presented. Trends in the frequency of cyclones and wind storms, as well as variations associated with the North Atlantic Oscillation (NAO), the East Atlantic/West Russian (EAWR) and the Scandinavian variability pattern (SCAND) are discussed.
\end{abstract}

The study is based on the ERA40 reanalysis dataset. Wind storm tracks are identified by tracking clusters of adjacent grid boxes characterised by extremely high local wind speeds. The wind track is assigned to a cyclone track independently identified with an objective scheme.

Areas with high wind activity - quantified by extreme wind tracks - are typically located south of the Golf of Genoa, south of Cyprus, southeast of Sicily and west of the Iberian Peninsula. About $69 \%$ of the wind storms are caused by cyclones located in the Mediterranean region, while the remaining $31 \%$ can be attributed to North Atlantic or Northern European cyclones.

The North Atlantic Oscillation, the East Atlantic/West Russian pattern and the Scandinavian pattern all influence the amount and spatial distribution of wind inducing cyclones and wind events in the MR. The strongest signals exist for the NAO and the EAWR pattern, which are both associated with an increase in the number of organised strong wind events in the eastern MR during their positive phase. On the other hand, the storm numbers decrease over the western MR for the positive phase of the NAO and over the central MR during the positive phase of the EAWR pattern. The positive phase of the Scandinavian pattern is associated with a decrease in the number of winter wind storms over most of the MR.

Correspondence to: K. M. Nissen (katrin.nissen@met.fu-berlin.de)
A third of the trends in the number of wind storms and wind producing cyclones during the winter season of the ERA40 period may be attributed to the variability of the North Atlantic Oscillation.

\section{Introduction}

Cyclones play an important role in the weather and climate of the Mediterranean region (MR) (Radinovic, 1987). The decrease in autumn and winter precipitation in past decades (e.g. Palmieri et al., 1991) has been, for example, associated with a reduction in the intensity of the strongest Mediterranean cyclones (Trigo et al., 2000). Wind storms are one of the natural hazards related to cyclones. A recent example is storm "Klaus" which caused peak gusts of over $200 \mathrm{~km} / \mathrm{h}$, extensive damage and fatalities in southern France and Spain in January 2009. While the link between strong precipitation and cyclone activity has been explored in many studies (e.g. Trigo et al., 2000), few studies investigated the link between cyclones and strong surface winds within the Mediterranean Basin.

Large-scale teleconnection patterns (e.g. described in Barnston and Livezey, 1987) can have an impact on the intensity and frequency of Mediterranean cyclones. Pinto et al. (2009) found more cyclones over the western MR during the negative phase of the North Atlantic Oscillation (NAO). Raible (2007) correlated cyclone strength with 500 $\mathrm{hPa}$ geopotential height and found that strong cyclones in southern Europe tend to occur during the negative phase of the NAO. Trigo et al. (2008) correlated wind speed with the NAO, the East Atlantic (EA) and the Scandinavian (SCAND) index. In the western MR they found a negative correlation for the NAO and a positive correlation for the EA and SCAND patterns. Other authors have analysed the influence

Published by Copernicus Publications on behalf of the European Geosciences Union. 
of large-scale patterns on precipitation, which is also caused by cyclones, in various regions of the MR (e.g. Krichak et al., 2000, 2002; Krichak and Alpert, 2005a,b). The main patterns they found to be important for the MR are the NAO, the SCAND and the East-Atlantic/West-Russian Pattern (EAWR). Furthermore, recent trends in the Mediterranean precipitation and cyclogenesis have been attributed to trends in the NAO and the EAWR patterns (e.g. Krichak and Alpert, 2005a,b; Trigo et al., 2000). Thus, understanding the link between these large-scale patterns and climate variables in the Mediterranean is essential in order to interpret the impact of climate change on Mediterranean climate.

A large number of cyclone algorithms have been used to compute cyclone climatologies from digital data (e.g. Murray and Simmonds, 1991; Hodges, 1995; Blender et al., 1997; Serezze et al., 1997). A number of studies have been conducted specifically for the Mediterranean region (e.g. Alpert et al., 1990; Trigo et al., 1999), using settings that take into account the size and strength of Mediterranean cyclones. The formation and passage of these cyclones can be associated with strong precipitation, surface winds, floods, thunderstorms, storm surges or landslides over the region. This paper focuses on cyclones that cause extreme wind events in the Mediterranean region. In the context of automatic cyclone detection, cyclones are often referred to as extreme if their intensity measured via the core pressure or the strength of the associated circulation exceeds a certain threshold (e.g. Raible et al., 2006). The systematic detection of hazardous systems, based on these cyclone characteristics, is complicated because no linear relationship exists between the intensity of cyclones (as defined above) and their associated impacts (e.g. Lionello et al., 2006). Furthermore, weather systems producing high impact weather over the Mediterranean sometimes propagate from the North Atlantic to central Europe (e.g. Homar et al., 2007; Raible, 2007) without entering the Mediterranean basin. Hence, a straightforward analysis of such systems, by analysing the dataset with a cyclone detection algorithm, is not possible. To overcome this problem, we have developed an impact-based approach; combining a cyclone detection technique with a wind track detection algorithm.

The remainder of the paper is organised as follows: in Sect. 2 the data and methodology to identify extreme cyclones are described. Validation case studies and the results of sensitivity tests are presented in Sect. 3. Section 4 contains a climatology of strong wind events affecting the Mediterranean region and associated extreme cyclones. The influence of large-scale teleconnection patterns on cyclones and high-wind events is analysed in Sect. 5, while Sect. 6 presents trends in cyclone numbers and strong wind events. Conclusions are given in Sect. 7.

\section{Method and data}

\subsection{Data}

We use the European Centre for Medium-Range Weather Forecast (ECMWF) ERA40 dataset (Uppala et al., 2005), with a horizontal resolution of $1.125^{\circ} \times 1.125^{\circ}$, and examine 45 extended winter seasons, covering the months from October to March, from 1957-2002. For the identification and tracking of cyclones, the mean sea-level pressure (MSLP) field is analysed, while the wind tracking scheme is applied to the instantaneous $10 \mathrm{~m}$ wind speed. The temporal resolution of the data is $6 \mathrm{~h}$.

The teleconnection indices used in Sect. 5 were obtained from the Climate prediction Centre of the National Oceanic and Atmospheric Administration web site (http://www.cpc. ncep.noaa.gov/data/teledoc/telecontents.shtml). They are based on rotated principal component analysis applied to monthly mean standardised $500 \mathrm{hPa}$ geopotential height anomalies (Barnston and Livezey, 1987).

\subsection{Wind tracking}

The first step necessary to determine cyclones associated with wind storms in the MR, is the detection of local strong wind events. This is realized by identifying grid boxes with wind speeds exceeding the local 98th percentile (determined per grid box for the extended winter season). The 98th percentile threshold values for ERA-40 are shown in Pinto et al. (2007; their Fig. 3a). Adjacent grid boxes form a wind cluster for which the geographic centre is determined. Clusters consisting of less than three grid boxes are disregarded, corresponding to a minimum affected size of approx. $46875 \mathrm{~km}^{2}$ (about one-sixth of the size of Italy). The wind clusters are then tracked using a nearest neighbour approach while checking for a level of shape similarity of at least $30 \%$. Only tracks existing over a period of at least $18 \mathrm{~h}$ are kept. Local short-term wind speed extremes, possibly incorporated in the wind tracks, are not considered in detail.

The method is further described in Leckebusch et al. (2008), where it was applied to North Atlantic and European storms. The threshold for the size of events was reduced (from 5 to 3 effected $1.125^{\circ} \times 1.125^{\circ}$ grid boxes) for this regional application, compared to the values of Leckebusch et al. (2008), in order to capture the smaller scale structures expected to be relevant in the MR.

\subsection{Cyclone tracking}

The cyclones responsible for the high wind events are detected by applying a cyclone identification and tracking algorithm to the MSLP field. The method was originally developed by Murray and Simmonds (1991) for the Southern Hemisphere and has been adapted to North Atlantic and Mediterranean cyclone characteristics by Pinto et al. (2005). To identify cyclones, the MSLP grid is scanned for maxima 
of the Laplacian of pressure $\left(\nabla^{2} p\right)$. The pressure minimum closest to the maximum in $\nabla^{2} p$ is defined as the low-pressure core. If such a minimum exists within a search radius of about $1200 \mathrm{~km}$, the system is classified as closed. If no such minimum can be found, the cyclone is classified as an open depression. In this case, the search is performed for the point with the minimum pressure gradient. To ensure that only weather relevant systems are kept, open depressions weaker than $\nabla^{2} p=0.2 \mathrm{hPa}$ (deg.lat) $)^{2}$ and closed systems weaker than $0.3 \mathrm{hPa}$ (deg.lat) ${ }^{2}$, as well as systems that are too close to other cyclones or located over high ground are disregarded.

In order to track the cyclones, a subsequent position and core pressure is predicted for each identified cyclone. The most likely cyclone identified in the following time step is then chosen as the next track element. In the case of splitting cyclones, the existing track is continued with the most probable cyclone core, while the other core is considered as a new system. For details of this method, see e.g. Murray and Simmonds (1991). The thresholds for rejecting spurious depressions and cyclone tracks have been modified over the Pinto et al. (2005) study, as the cyclone results are sensitive to data resolution (cf. Blender and Schubert, 2000; Zolina and Gulev, 2002). This shows in higher values for the Laplacian of pressure in the better resolved ERA40 dataset compared to the NCEP reanalysis data analysed in Pinto et al. (2005). Compared to Table 1 from Pinto et al. (2005), we have changed, for the identification, the minimum $\nabla^{2} p$ values for open, closed and strong systems: $c$ mnc $1=0.2 ;$ cmnc $2=0.3$; $\mathrm{cmncw}=0.7$, which gives the best results for the increased spatial resolution. Additionally, spurious cyclones with core pressure above $1025 \mathrm{hPa}$ were removed. For the tracking, we have set the devaluation threshold for new systems to qmxnew $=0.8$ for the same reason. Only cyclones tracked over a period of at least $24 \mathrm{~h}$ (5 ERA40 time steps) are kept. In total, the obtained cyclone climatology (cf. Fig. 1 top) is comparable to the NCEP climatology presented in Pinto et al. (2005).

\subsection{Wind and cyclone matching}

The final step is to select the cyclones responsible for the wind speed exceedances from the complete set of identified cyclones. The wind tracks are matched to the most likely cyclone tracks in three iterations. First, wind events that have been caused by a single cyclone are matched: for each wind cluster track, all cyclone tracks that cover the complete period of the wind exceedance are singled out and the mean distance between the cyclone position and the location of the wind cluster centre is determined for the duration of coexistence. If more than one cyclone, with a mean distance of less than $800 \mathrm{~km}$, is found the strongest cyclone in terms of the Laplacian of pressure is selected. Otherwise, the closest cyclone with a mean distance of less than $1200 \mathrm{~km}$ is chosen. The threshold of $1200 \mathrm{~km}$ maximum distance between wind track centre and cyclone centre corresponds to
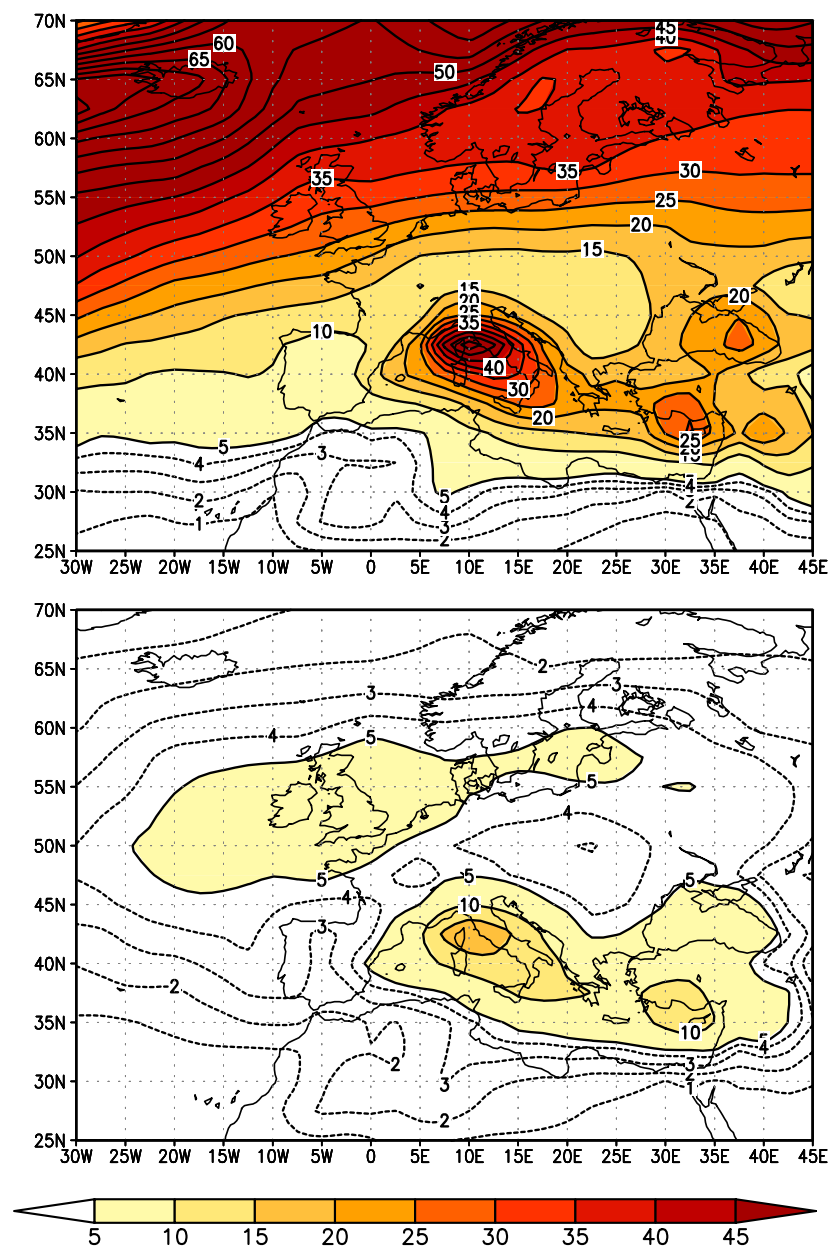

Fig. 1. Cyclone track density in number of cyclones per extended winter season per (deg.lat.) ${ }^{2}$. Top: for all cyclones. Bottom: for all cyclones causing storm in the Mediterranean region.

the search radius for the cyclone core around the Laplacian of pressure maximum in the cyclone identification scheme. $1840(71.2 \%)$ wind events effecting the Mediterranean region $\left(10^{\circ} \mathrm{W}-40^{\circ} \mathrm{E} / 30^{\circ} \mathrm{N}-46^{\circ} \mathrm{N}\right)$ are matched during the first iteration. The remaining wind tracks cannot be matched to a single cyclone but are the result of two consecutive depressions. In this case, a second search is conducted. This time the cyclone exhibiting the longest period of coexistence to the wind cluster track is chosen. The period of coexistence must cover at least 4 time steps and a mean distance of $1200 \mathrm{~km}$ must not be exceeded. $353(13.7 \%)$ of the wind tracks are matched during the second iteration.

The search, during the first two iterations, is conducted amongst cyclones that have been closed and stronger than $0.7 \mathrm{hPa} /(\text { deg.lat })^{2}$ at least once during their lifetime. In the Mediterranean region, local effects can sometimes generate cyclones that never become closed during their lifetime, but still have an impact. Therefore, a third matching iteration is performed. The search is conducted for the open depression 


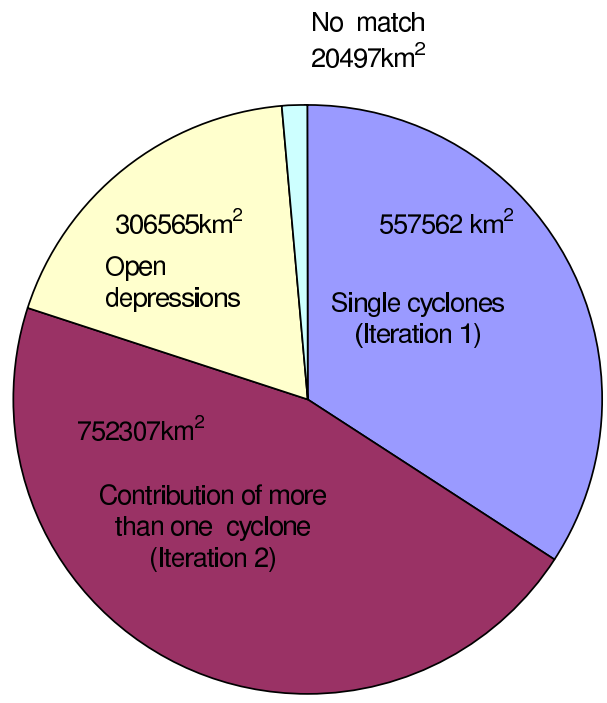

Fig. 2. Average size of area affected by wind events above the local 98th percentile in the Mediterranean region.

exhibiting the longest period of coexistence (at least 4-timesteps on average below $1200 \mathrm{~km})$. This concerns $188(7.3 \%)$ wind events.

The remaining $7.8 \%$ are mostly the result of two wind cluster tracks accidentally joined by the wind cluster tracking algorithm. Individually they fall below the 4-time-step threshold for the wind cluster tracking and can be disregarded. A minor number of the unmatchable wind events is caused by cyclones that leave the cyclone tracking area and propagate southwards (of $20^{\circ} \mathrm{N}$ ).

The average area (footprint) affected by wind speed events above the local 98th percentile in the MR, which have been matched during the first iteration (i.e. to individual mature cyclones), is more than $557000 \mathrm{~km}^{2}$ (Fig. 2). As could be expected, the average area affected by wind cluster tracks matched during the second iteration of the matching algorithm, which assigns those wind events that have been caused by two consecutive cyclones, is larger than this $\left(752000 \mathrm{~km}^{2}\right)$. Depressions that have never been closed during their lifetime cause smaller scale wind exceedances (on average $307000 \mathrm{~km}^{2}$ ). The area, affected by those wind events which couldn't be attributed to cyclones, is more than one order of magnitude smaller than those of the attributed wind events, confirming that the most relevant events are captured by the wind and cyclone matching technique.

\subsection{Cyclone catalogues}

The final product of this methodology are two cyclone catalogues. The first catalogue contains all cyclones that have been identified and tracked during the extended winter season (October-March) north of $20^{\circ} \mathrm{N}$, irrespective of a possible association with a wind track. Only cyclones that have been closed and stronger than $0.7 \mathrm{hPa} /(\mathrm{deg} .1 \mathrm{lat})^{2}$ at least once during their lifetime are included (62 405 cyclones). From the first catalogue, a subset of 4407 cyclones cross the Mediterranean region $\left(10^{\circ} \mathrm{W}-40^{\circ} \mathrm{E} / 30^{\circ} \mathrm{N}-46^{\circ} \mathrm{N}\right)$. Of these $28 \%$ (1228) are associated with wind tracks. The second catalogue contains the 2058 cyclones responsible for 2381 wind events which made an impact in the MR (including the 1228 cyclones mentioned above, 188 open depressions crossing the MR and 642 cyclones passing outside the MR). The characteristics of extreme cyclones relevant for the MR can now be studied by comparing the Mediterranean subset of the first cyclone catalogue to the second cyclone catalogue.

For the remainder of this paper, MR always refers to the area $10^{\circ} \mathrm{W}-40^{\circ} \mathrm{E} / 30^{\circ} \mathrm{N}-46^{\circ} \mathrm{N}$ (see the gray rectangle in Fig. 6).

\section{Validation}

\subsection{Case studies}

In order to demonstrate the ability of the wind-cluster tracking approach to identify relevant storm events in the Mediterranean region and match them with the appropriate cyclone, two examples are presented. Figs. 3-4 show the cyclone track (red) and wind-cluster track (blue) together with the mean sea-level pressure field for the time step marked in green on both tracks and the wind speed exceeding the local 98th percentile for two selected cases. The cyclone located close to the Golf of Genoa on 18 November 1975, 06:00 GMT caused flooding in the lagoon of Venice. The 98th wind speed percentile in the MR was exceeded for a duration of $48 \mathrm{~h}$. The total area affected by high winds during this period is displayed in gray (Fig. 3), while the area affected at 06:00 GMT 18 November 1975 is highlighted using colour shading. The cyclone developed at the edge of a strong low pressure system located over the British Isles. It was first detected over France and entered the MR over the Golf of Lion. The cyclone then propagated towards the north-western Italian coast and remained west of Italy until it decayed. The wind track (blue line, Fig. 3), connecting geographical centres of the exceedance wind field rather than the location of the maximum wind speed, shows that high winds persisted in the area over an extended period. This is an important requirement for a strong sea surge in Venice (cf. Trigo and Davies, 2002).

The second example (Fig. 4) shows the synoptic situation on 8 December 2001, 00:00 GMT. A Mediterranean cyclone originating from the central Mediterranean basin propagates north-eastward. Wind speeds exceeding the 98th percentile accompany the cyclone on its south-eastern and its northwestern edge. This example illustrates the ability of the matching algorithm to assign more than one wind track to a cyclone if appropriate. It also demonstrates that Mediterranean cyclones do not have to exhibit exceptional deep cores in order to cause strong winds. In this particular case, the cyclone's core pressure never reached values below $1000 \mathrm{hPa}$. 


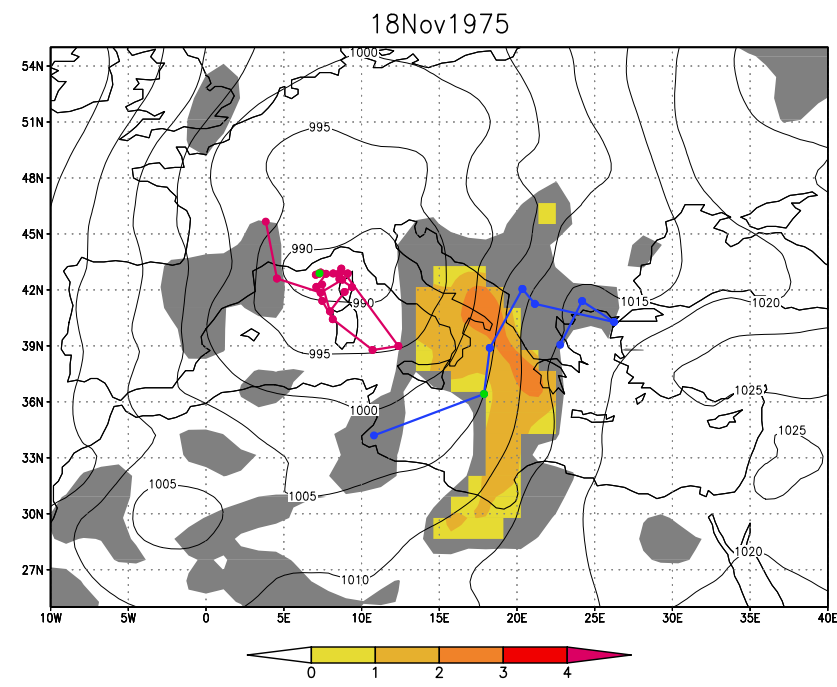

Fig. 3. Cyclone track (red), wind-cluster track (blue), mean sealevel pressure field (isolines in $\mathrm{hPa}$ ) and exceedance of 98th percentile of wind speed (coloured shading in $\mathrm{m} / \mathrm{s}$ above local 98th percentile) for 18 November 1975 06:00 GMT. Green dots indicate position of current cyclone core and wind cluster centre. The total area with wind speeds exceeding the 98th percentile over the 2 day period is shown in gray. The event has caused flooding in Venice.

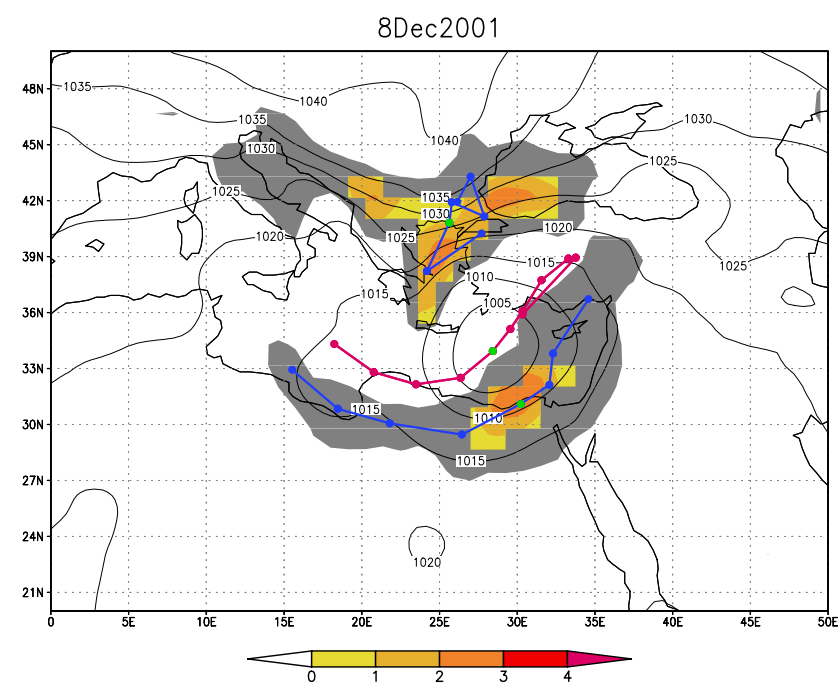

Fig. 4. Cyclone track (red), wind-cluster track (blue), mean sealevel pressure field (isolines in hP) and exceedance of 98th percentile of wind speed (coloured shading in $\mathrm{m} / \mathrm{s}$ above local 98th percentile) for 8 December 2001 00:00 GMT. Green dots indicate position of current cyclone core and wind cluster centre. The total area with wind speeds exceeding the 98th percentile over the 2-day period is shown in gray.

It should be noted that the quality of the ERA40 dataset may be a limiting factor for the performance of the method. Medium-scale cyclones and the winds associated with them are occasionally underestimated in the ERA40 dataset so that some historical events (e.g. mid-latitude storm "Lothar" 26 December 1999) are not fully captured in the numerical analysis procedure (e.g. Ulbrich et al., 2009).

\subsection{Sensitivity tests}

The robustness of the results obtained by the wind and cyclone matching technique has been explored by conducting a number of sensitivity tests.

All analyses shown in this paper have been repeated with a subset of the hazardous cyclones and wind cluster tracks, using only the $71 \%$ of cyclones and wind tracks that could be matched unambiguously (i.e. matched during the first iteration). While this change obviously decreases the total numbers, it has no impact on the spatial distribution of the events.

Tracking wind clusters exceeding the local 95th percentile instead of the local 98th percentile leads to an increase in the number of affected grid boxes and makes the separation of the affected areas into individual wind tracks more difficult. It leads to a higher rate of wind tracks caused by consecutive cyclones that have been joined by the wind cluster tracking algorithm and complicates the correct attribution to the responsible cyclones. The spatial structures of the wind cluster track density, however, are not altered.

A reduction of the required number of grid boxes with wind speeds exceeding the local 98th percentile from three to two, increases the number of captured wind events in the Mediterranean region by $20-50 \%$ but reduces the spatial structures. This is not surprising, since allowing for less organised systems by decreasing the number of grid boxes or time steps will eventually lead to a uniform distribution with winds exceeding the 98 th percentile at $2 \%$ of the time.

\section{Climatology of Mediterranean storms and impact relevant cyclones}

The cyclone track density is a measure of the spatial distribution of cyclone activity. Shown in the top panel of Fig. 1 is the cyclone track density in number of cyclones per extended winter season and per (deg.lat.) $)^{2}$ calculated with an averaging radius of 3 degrees. There is a general decrease in the number of cyclones from Iceland towards the south. In winter, the MR exhibits two local maxima. One is located over the Golf of Genoa and the other is located in the vicinity of Cyprus.

The track density for the subset of cyclones that have caused strong wind events in the MR is displayed in the bottom panel of Fig. 1. A majority (69\%) of the cyclones, responsible for high wind in the MR, also passes over the Mediterranean basin. A secondary cyclone track maximum is located over the British Isles. This illustrates the importance of non-local cyclones that affect the region in addition to strong local systems. 


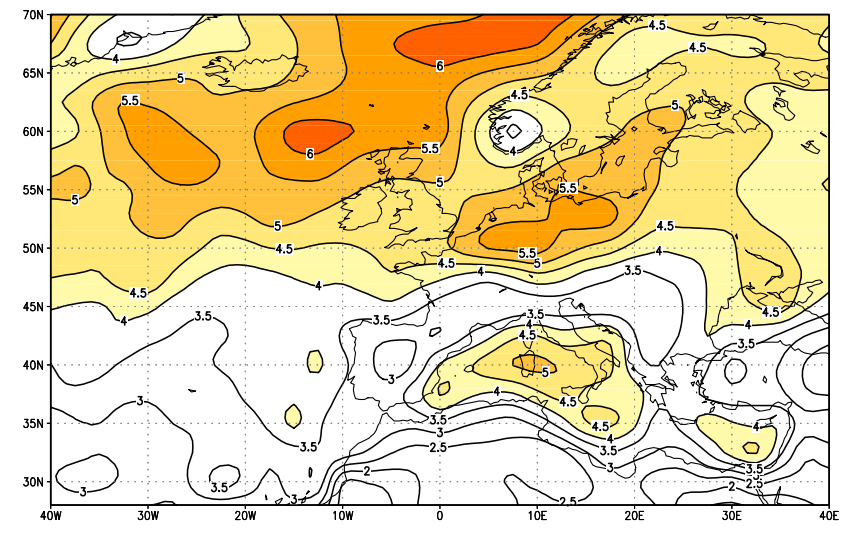

Fig. 5. Wind-cluster track density. For 45 extended winter seasons (ONDJFM). In number of events/winter/(deg.lat.) ${ }^{2}$.

The wind cluster track density (Fig. 5) shows a general decrease in the number of events per winter season from the north towards the south, which is in agreement to the cyclone track density (Fig. 1). The track maximum in the Eastern North Atlantic, associated with the North Atlantic cyclone track, is clearly identified. A second maximum is located over the continent in central Europe. The area of the highest wind activity in the MR is located over the western Mediterranean area with a maximum around Corsica and Sardinia. The region covered by enhanced numbers of wind events reaches to southern Italy and to Sicily, corresponding to wind regimes south of the typical routes found for travelling cyclones originating over the Golf of Genoa by Trigo et al. (1999). In the eastern part of the Mediterranean, a local wind track maximum is located south of Cyprus, associated with Cyprus Lows (e.g. Alpert et al., 2004). With respect to the distance between the cyclone cores and the centres of the wind cluster tracks, distances between 400 and $600 \mathrm{~km}$ were found in $28 \%$ of the times, between 600 and $800 \mathrm{~km}$ in $21 \%$ of the times, taking all three matching steps from Sect. 2.4 into account. Distances below $200 \mathrm{~km}$ rarely occur.

Figure 6 depicts the location of the cyclone centres and their intensity in terms of the Laplacian of pressure $\left(\nabla^{2} p\right)$ at the time of highest absolute wind speed in the Mediterranean area (gray rectangle). The distribution of cyclones resembles the track density pattern (Fig. 1 bottom), with most cyclones located locally and a secondary maximum located over the north-eastern Atlantic region. The highest $\nabla^{2} p$ values can be found for cyclones positioned over the north-eastern Atlantic region with $\nabla^{2} p$ values of more than $3 \mathrm{hPa} /(\text { deg.lat })^{2}$. The highest $\nabla^{2} p$ values at the time of highest wind speed for Mediterranean cyclones are associated with cyclones located near the western coast of Italy (more than $2 \mathrm{hPa} /(\text { deg.lat) })^{2}$ ). In the southern MR, the number of cyclones causing storms in the area is small and comparatively weak. The wide range of intensities in terms of $\nabla^{2} p$ confirms that it is impossible to deduce the occurrence of wind storms from the intensity

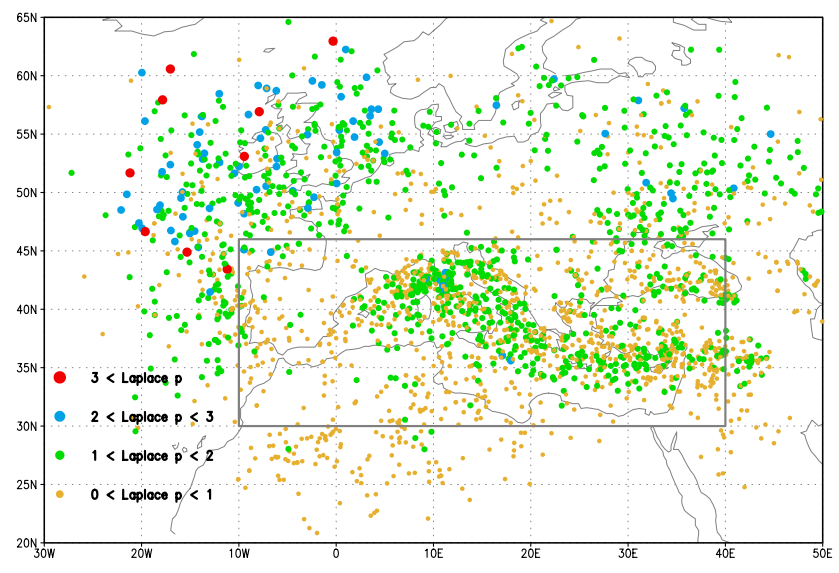

Fig. 6. Position of cyclone causing wind storm in the Mediterranean region. Location shown at time of highest wind speed. The colour coding and size of the circles reflect the strength of the cyclones via $\nabla^{2} p$

Table 1. Strength of cyclones crossing the Mediterranean region (based on Laplacian of pressure in $\mathrm{hPa} /(\mathrm{deg} .1 \mathrm{lat})^{2}$ ) for cyclones associated with strong wind (middle column) and all cyclones (right column). In percentage of events.

\begin{tabular}{ccc}
\hline Laplace pressure & Storm causing & All \\
\hline $0.5-1.0$ & 29.5 & 46.8 \\
$1.0-1.5$ & 47.9 & 40.0 \\
$1.5-2.0$ & 17.0 & 10.1 \\
$2.0-2.5$ & 4.0 & 2.2 \\
$2.5-3.0$ & 1.3 & 0.7 \\
$3.0-3.5$ & 0.3 & 0.2 \\
$3.5-4.0$ & 0.1 & 0.1 \\
\hline
\end{tabular}

of the cyclones, which stresses the usefulness of choosing an impact-based approach in order to identify extreme cyclones relevant to the MR. Nevertheless, a comparison of cyclone strength for all cyclones crossing the MR and the subset associated with strong wind events reveals that the percentage of cyclones exhibiting values of the Laplacian of pressure of more than $1 \mathrm{hPa} /(\mathrm{deg} . l \mathrm{lat})^{2}$ is higher for the cyclones causing the wind events (Table 1).

Most cyclones in the first catalogue which cross the MR (i.e. systems belonging to the MR subset) are of Mediterranean origin (Fig. 7). The main region of cyclogenesis is located over the Golf of Genoa. Of the cyclones located over the MR during (at least) part of their life time, 34\% develop in the western Mediterranean region $\left(10^{\circ} \mathrm{W}-15^{\circ} \mathrm{E} / 30^{\circ} \mathrm{N}-\right.$ $\left.46^{\circ} \mathrm{N}\right)$ and $33 \%$ in the eastern Mediterranean region $\left(15^{\circ} \mathrm{E}-\right.$ $40^{\circ} \mathrm{E} / 30^{\circ} \mathrm{N}-46^{\circ} \mathrm{N}$ ). Only $14 \%$ of the cyclones crossing the MR originate over the northern Atlantic, while the other directions add up to a total of $15 \%$. This distribution 

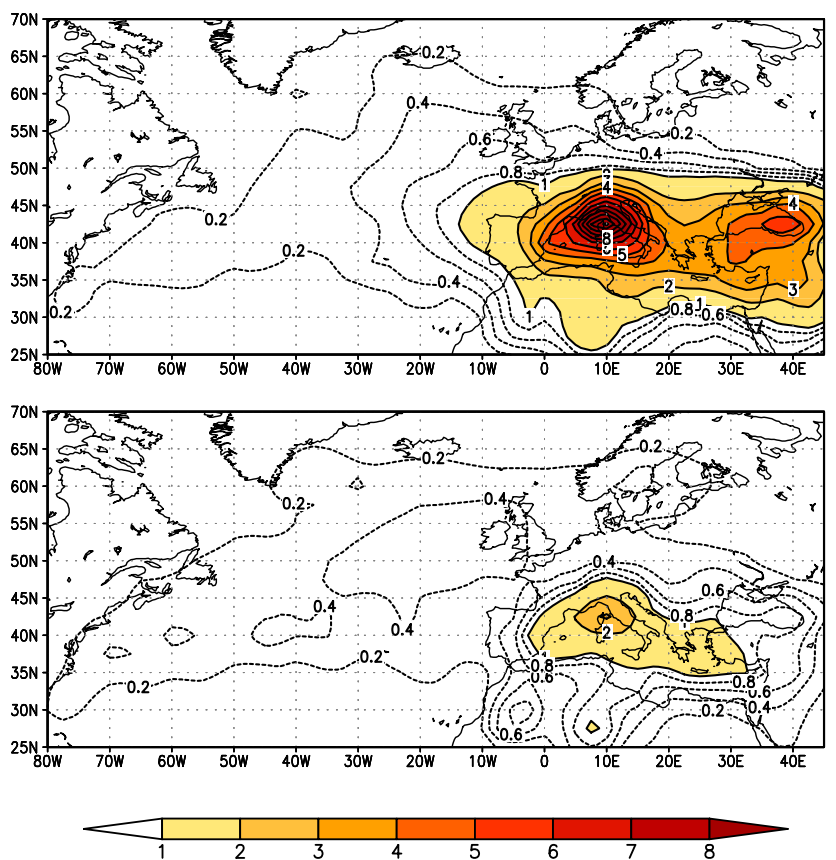

Fig. 7. Cyclogenesis for the extended winter season (ONDJFM) in events/winter/(deg.lat. $)^{2}$. Top: for all cyclones crossing the Mediterranean region. Bottom: for all cyclones causing wind storm in the Mediterranean region.

becomes quite different when considering the cyclones that have caused wind events in the MR. The percentage of cyclones originating over the North Atlantic region more than doubles and makes a greater contribution to the total number of storm-relevant cyclones than the western Mediterranean region. The contribution of the eastern MR decreases from $33 \%$ to $19 \%$. The other directions contribute with a total of only $24 \%$ (Table 2 ).

\section{Links to large-scale patterns}

In this section, the influence of the NAO, the EAWR and the SCAND pattern on cyclones and extreme wind events in the MR is analysed. The cyclones and wind events have been divided into two groups, those first occurring during a month associated with a positive phase (an index value greater than 0 ) of the teleconnection pattern and those generated during months exhibiting a negative phase. The differences are displayed in units of number of events per 6 month winter season and area. Figure 8 depicts the difference of the cyclone track density between the positive and negative phase of the NAO (top), EAWR (middle) and SCAND (bottom) patterns. Shaded are significance levels above $90 \%$ and $99 \%$ determined using the Student's $t$-test on a monthly basis. As expected from previous studies (e.g. Hurrell and van Loon, 1997) during the positive NAO phases, the storm track is intensified and shifted northward (Fig. 8a). During the negative phase of the NAO, the cyclone tracks are located further
Table 2. Area of genesis for cyclones crossing the Mediterranean and for cyclones causing storm in the Mediterranean region.

\begin{tabular}{lcc}
\hline & $\begin{array}{l}\text { Cyclones } \\
\text { crossing MR }\end{array}$ & $\begin{array}{c}\text { Cycl. causing } \\
\text { storm in MR }\end{array}$ \\
\hline Atlantic $\left(<10^{\circ} \mathrm{W}\right)$ & $650(14 \%)$ & $668(32 \%)$ \\
South $\left(10^{\circ} \mathrm{W}-40^{\circ} \mathrm{E} /<30^{\circ} \mathrm{N}\right)$ & $237(5 \%)$ & $189(9 \%)$ \\
East $\left(>40^{\circ} \mathrm{E}\right)$ & $182(4 \%)$ & $85(4 \%)$ \\
North $\left(10^{\circ} \mathrm{W}-40^{\circ} \mathrm{E} />46^{\circ} \mathrm{N}\right)$ & $303(6 \%)$ & $229(11 \%)$ \\
West Mediterranean & $1542(34 \%)$ & $479(23 \%)$ \\
$\left(10^{\circ} \mathrm{W}-15^{\circ} \mathrm{E} / 30^{\circ} \mathrm{N}-46^{\circ} \mathrm{N}\right.$ & & \\
East Mediterranean & $1490(33 \%)$ & $407(19 \%)$ \\
$\left(15^{\circ} \mathrm{E}-40^{\circ} \mathrm{E} / 30^{\circ} \mathrm{N}-46^{\circ} \mathrm{N}\right)$ & & \\
Total & 4407 & 2058 \\
\hline
\end{tabular}

south resulting in more cyclone activity in the MR. This signal is significant over the western MR. The Mediterranean signal is strongest over the Golf of Genoa with an average of 9 additional cyclones per winter season during the negative phase of the NAO compared to its positive phase. A significant increase in the number of cyclones during the positive phase of the NAO is present at the southeastern Mediterranean shore (e.g. Israel). The dependence of the number of cyclones on the strength of the teleconnection indices is further explained in Table 3 distinguishing 5 classes of the monthly index value. The index values of all three patterns considered more or less follow a Gaussian distribution. The expected number of cyclones can be computed for each category from the long-term average (corresponding to $100 \%$ in each category in Table 3). The observed numbers listed in Table 3 differ systematically from these expected values. For the NAO, there is a decrease in the number of cyclones crossing the MR with increasing NAO index. The small area with a positive phase relation between NAO and a cyclone number over Israel (Fig. 8a) is too small to mask this relationship.

The cyclone track density difference for the two NAO phases, calculated only for cyclones associated with strong wind events in the MR, is displayed in Fig. 9a. The regional distribution resembles the one found for the total number of cyclones but the differences between counts for positive and negative NAO phase are disproportionally smaller in the area with positive differences north of $50^{\circ} \mathrm{N}$, owing to the smaller overall number of strong Mediterranean wind events associated with cyclones in this area.

The influence of the NAO phase and its strength on cyclones associated with wind events in the MR is summarised in the second column of Table 3. A slight increase can be observed in the number of events during the negative phase of the NAO. This relationship is, however, not very pronounced as a decrease in the number of cyclones associated with winds in the MR which themselves cross the MR is accompanied by an increase of wind producing cyclones passing over Northern Europe (Fig. 8a). 
a) NAO

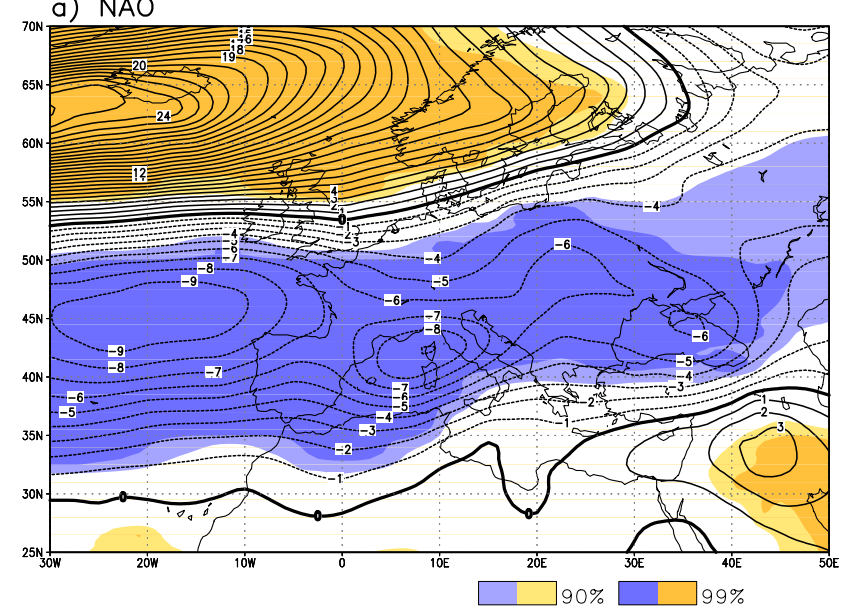

b) EAWR

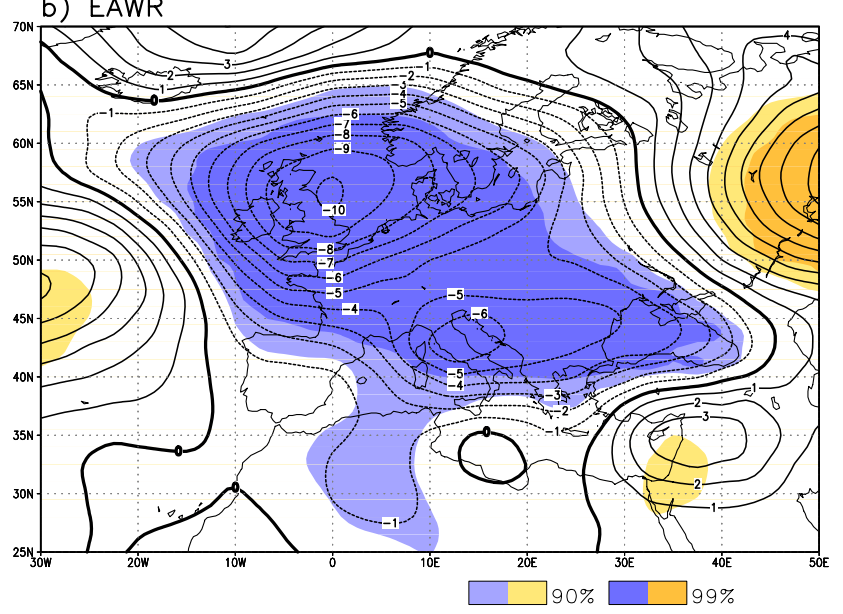

c) SCAND

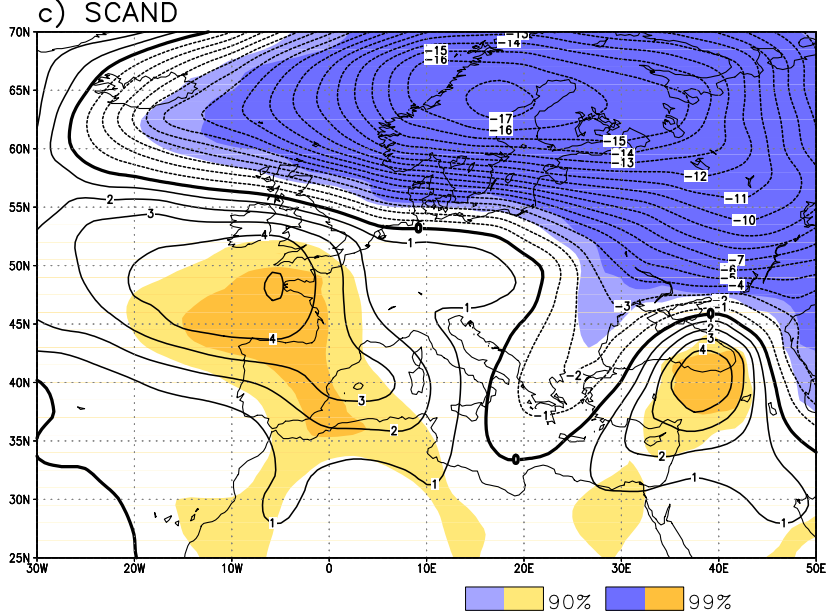

Fig. 8. Cyclone track density difference between positive and negative phase of large-scale pattern. Calculated for extended winter season. (a) NAO, (b) East-Atlantic West-Russian pattern, and (c) Scandinavian pattern. Shaded are $90 \%$ and $99 \%$ significance levels. Contour lines denote change in number of cyclones per extended winter season (ONDJFM) per (deg.lat.) ${ }^{2}$.
The evaluations using cyclone track density capture the cyclones over their entire life cycle including non-impactrelevant periods. Focussing on the effect of the largescale teleconnection patterns on wind track density directly (Fig. 10) reveals a pattern of NAO influence different from that found for the cyclone track density. The decrease of the number of high wind speed events in the MR during the positive phase of the NAO is confined to the south-western MR, while the wind activity over the middle and eastern part of the Mediterranean basin actually increases. This effect was masked by the non-wind relevant tails of the cyclone tracks in Fig. 9. The source of the additional wind tracks in the middle and eastern MR is revealed when analysing cyclogenesis for the positive and negative phase of the NAO. There is an increase in the number of cyclones generated in the eastern part of the Mediterranean basin during the positive phase of the NAO (Fig. 11). The increase in the number of wind events over northern Italy is associated with an increase in the number of cyclones developing over the Golf of Genoa (not significant) as well as with an increase in the number of northern European cyclones.

The magnitude of the influence of the EAWR phase on Mediterranean cyclones is comparable to that of the NAO. The number of cyclones passing the northern MR is reduced during the positive phase of the EAWR with the strongest reduction over Mid-Italy and the Adriatic basin with an average of 6 cyclones per winter season (Fig. 8b). In contrast to this, the Levant region is affected by more cyclones during the positive phase of the EAWR pattern. This is in agreement with studies analysing precipitation in Israel which found an increase in precipitation during the positive phase of the EAWR (Krichak et al., 2004, 2002).

The spatial distribution of the areas with significant changes in the number of cyclones associated with strong winds in the MR depending on the phase of the EAWR resembles that of the influence on the total cyclone numbers. Integrated over the entire MR, a positive phase of the EAWR is associated with a decrease both in the total number of cyclones passing the MR and in the number of cyclones associated with strong winds in the MR (Table 3).

The positive phase of the EAWR is also associated with a significant decrease in the number of wind events over the western Mediterranean basin with the strongest influence located over Italy ( 2 events per winter season) and a significant increase over the eastern MR (Fig. 10).

A weaker influence on cyclones and wind tracks over the MR is found for the Scandinavian pattern (Figs. 8c, 9c, and $10 \mathrm{c})$. A positive phase of SCAND is associated with an increase of the total number of winter cyclones in the western and eastern MR (Fig. 8c), which is also reflected in the SCAND/MEDCROSS column of Table 3. The increase in the number of wind relevant cyclones associated with the positive phase of SCAND is annihilated by the decrease of Northern European cyclones influencing the MR, leading to an overall increase in the number of cyclones with wind 
Table 3. Average number of cyclones per month depending on phases of teleconnection patterns. Notation: ++ index $>1.5,+1.5 \geq$ index $>0.5$, $0,0.5 \geq$ index $\leq-0.5,--0.5>$ index $\geq-1.5,--$ index $<-1.5$. Percentage values in parentheses are given with respect to the average number of events within the extended winter season. MEDCROSS designates cyclone tracks that have been inside the MR box within their life time, while MEDSTORM designates tracks assigned to an extreme wind track.

\begin{tabular}{lllllll}
\hline Phase & $\begin{array}{l}\text { NAO } \\
\text { MEDCROSS }\end{array}$ & $\begin{array}{l}\text { NAO } \\
\text { MEDSTORM }\end{array}$ & $\begin{array}{l}\text { EAWR } \\
\text { MEDCROSS }\end{array}$ & $\begin{array}{l}\text { EAWR } \\
\text { MEDSTORM }\end{array}$ & $\begin{array}{l}\text { SCAND } \\
\text { MEDCROSS }\end{array}$ & $\begin{array}{l}\text { SCAND } \\
\text { MEDSTORM }\end{array}$ \\
\hline-- & $20.5(125.8 \%)$ & $8.8(115.8 \%)$ & $18.8(115.3 \%)$ & $8.6(113.2 \%)$ & $13.0(79.8 \%)$ & $8.0(105.3 \%)$ \\
- & $17.5(107.4 \%)$ & $7.6(100 \%)$ & $18.0(110.4 \%)$ & $8.4(110.5 \%)$ & $15.9(97.5 \%)$ & $7.8(102.6 \%)$ \\
0 & $16.5(101.2 \%)$ & $7.4(97.4 \%)$ & $15.6(95.7 \%)$ & $7.5(98.7 \%)$ & $17.1(104.9 \%)$ & $7.8(102.6 \%)$ \\
+ & $14.9(91.4 \%)$ & $7.5(98.7 \%)$ & $15.5(95.1 \%)$ & $7.0(92.1 \%)$ & $16.3(100.0 \%)$ & $7.2(94.7 \%)$ \\
++ & $12.4(76.1 \%)$ & $7.6(100 \%)$ & $15.0(92.0 \%)$ & $7.0(92.1 \%)$ & $17.4(106.7 \%)$ & $7.0(92.1 \%)$ \\
total & 4407 & 2058 & 4407 & 2058 & 4407 & 2058 \\
\hline
\end{tabular}

affecting the MR (Table 3, last column). This is reflected in Fig. 10c showing a slight decrease in the number of wind events over most of the MR associated with a positive phase of the Scandinavian pattern.

\section{Trends}

Linear trends in cyclone numbers over the MR for the 45 winter seasons of the ERA40 dataset are displayed in Fig. 12 top. In line with the results of other authors (e.g. Trigo et al., 2008; Trigo, 2005; Maheras et al., 2001), a significant decrease can be found over the western Mediterranean basin and over the Black Sea, while the number of cyclones over the Levant region has increased.

The wind track density (Fig. 12 bottom) also displays a significant decrease in the number of wind events in the western Mediterranean region. Over Israel, the number of wind events is increasing in agreement to the increase of the total number of cyclones in this regions. The trend in the midMediterranean basin is positive with significant values found over the Golf of Genoa.

The spatial distribution of the trends in cyclone track density for the total number of cyclones, the number of cyclones associated with strong wind events (not shown), as well as the trends in wind track density bear a close resemblance to the pattern found for the dependence of event numbers on the phase of the NAO. A trend analysis of the extended winter season NAO index over the ERA40 period confirms that the NAO index, in fact, exhibits a significant positive trend ( 0.18 units per 10 winter seasons). Moreover, a correlation analysis of cyclone numbers with the NAO index, reveals a significant negative correlation (correlation coefficient of up to 0.3 ) in the western MR and a significant, positive correlation at the southeastern Mediterranean shore, which also supports the assumption that the trends observed during the winter season of the ERA40 period are at least partially related with the NAO variability. A linear regression analysis between the NAO index and cyclone numbers suggests that one third of the trend in the MR can be attributed to the observed NAO trend during the ERA40 period (not shown).
The Scandinavian pattern exhibits a slightly negative trend for the winter months from 1957 to 2002, while no trend can be detected for the EAWR index. The linear regression confirms that the contribution of these patterns to the overall trend can be regarded negligible.

\section{$7 \quad$ Discussion and conclusions}

An impact based method is used to identify extreme cyclones with respect to wind based on the ERA40 dataset, analysing 45 extended winter seasons. The approach overcomes the problem that no linear relationship exists between cyclone strength in terms of the Laplacian of pressure or cyclone core pressure and its impact on the Mediterranean region. It also allows the taking of non-local cyclones, having an impact on the MR, into account.

While it is based on a local definition of impact relevant wind speeds (excess of the local 98th quantile), the definition of extreme wind events additionally requires that thresholds for the spatial extend and duration are exceeded. The occurrence of such events is not necessarily evenly distributed over the area considered. In fact, different regions with an enhanced frequency of extreme wind tracks are identified within the MR. The most active region is located south of the Golf of Genoa and associated with Genoa lows. Cyprus lows are also associated with enhanced wind activity. Further regions of strong wind activity exist west of the Iberian Peninsula and south east of Sicily.

The influence of three large-scale teleconnection patterns (NAO, EAWR, and SCAND) on cyclone and wind activity in the MR has been analysed for the extended winter seasons of the ERA40 period. The strongest influence is found for the NAO and the EAWR pattern. The NAO and EAWR pattern are both associated with an increase in the number of strong wind events in the eastern MR during their positive phase. The positive phase of the NAO is, moreover, associated with a decrease in the number of extreme wind tracks in the western MR region, while there is a decrease over the central MR during the positive phase of the EAWR teleconnection 
a) $\mathrm{NAO}$

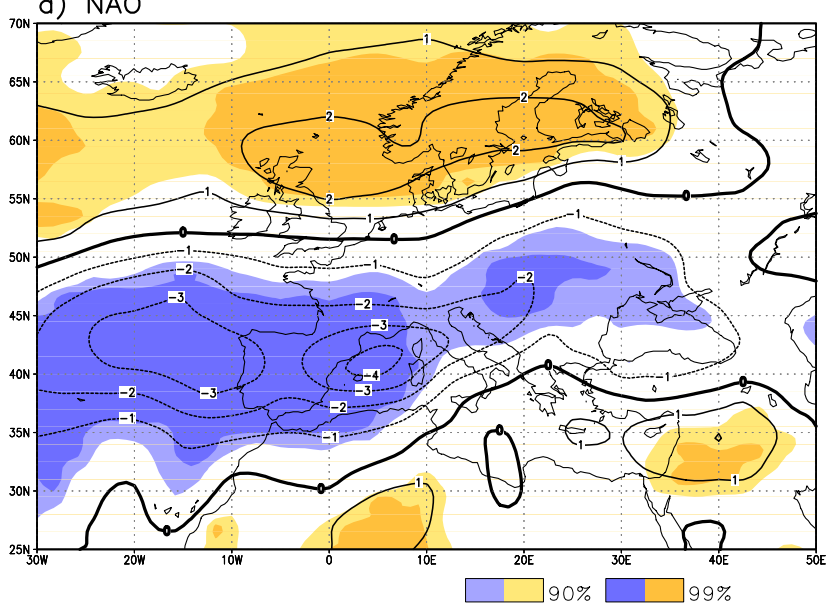

b) EAWR

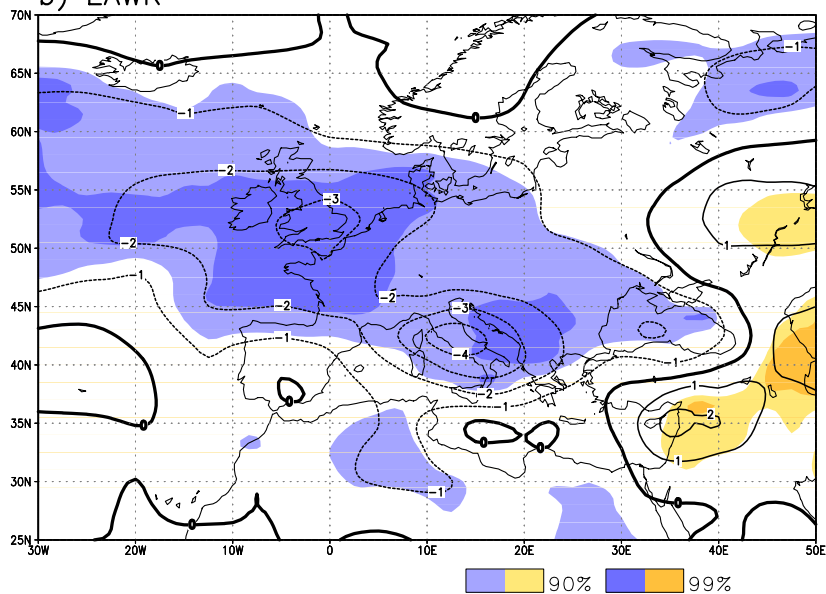

c) SCAND

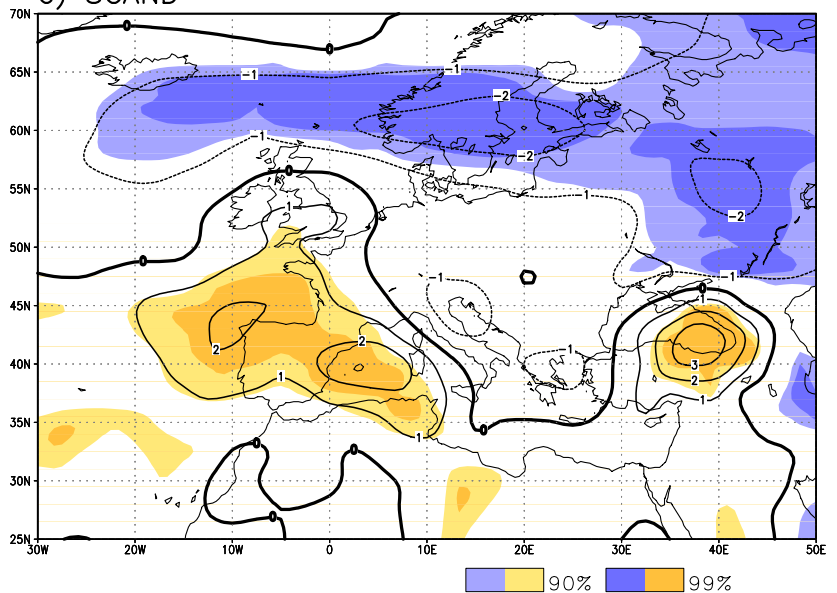

Fig. 9. As Fig. 8 but considering only cyclones that have caused wind storms in the Mediterranean region. (a) NAO, (b) East-Atlantic West-Russian pattern, and (c) Scandinavian pattern. Shaded are $90 \%$ and $99 \%$ significance levels. Contour lines denote change in number of cyclones per extended winter season (ONDJFM) per (deg.lat. $)^{2}$.
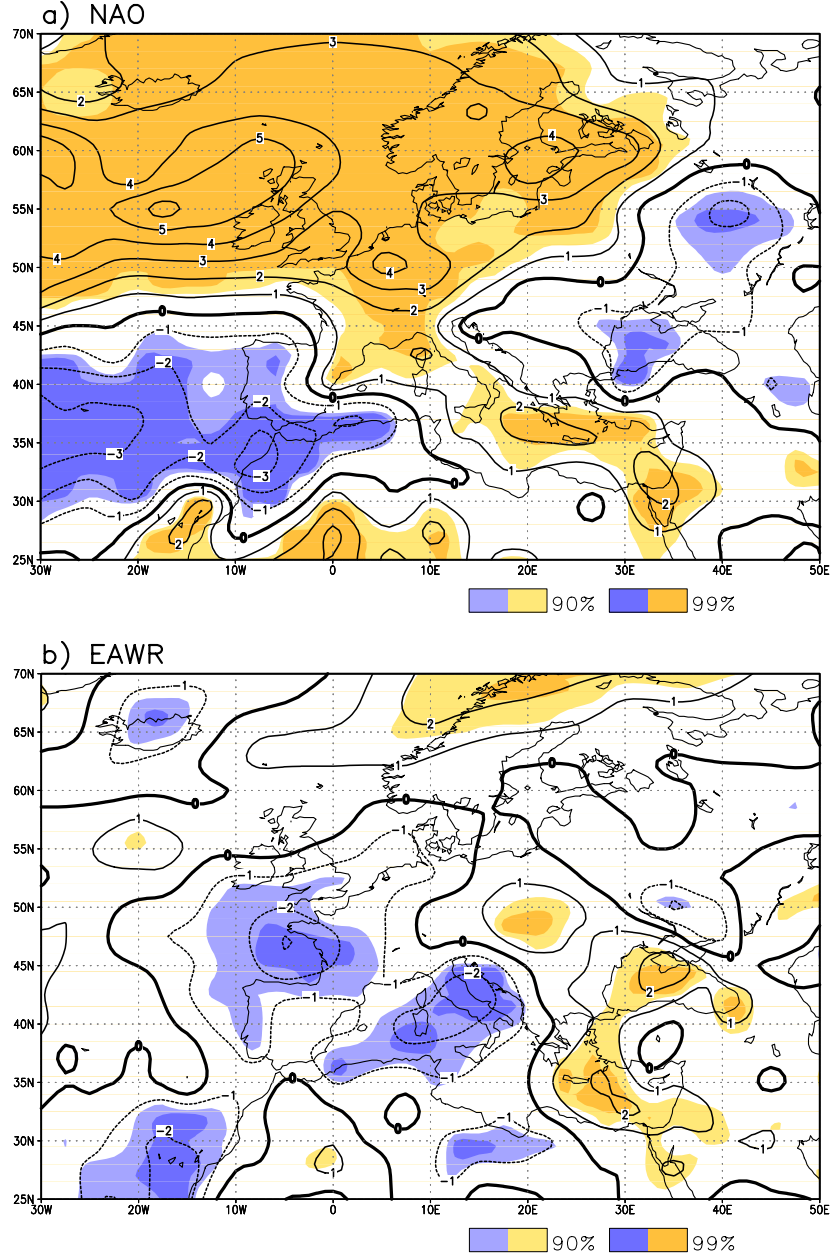

c) SCAND

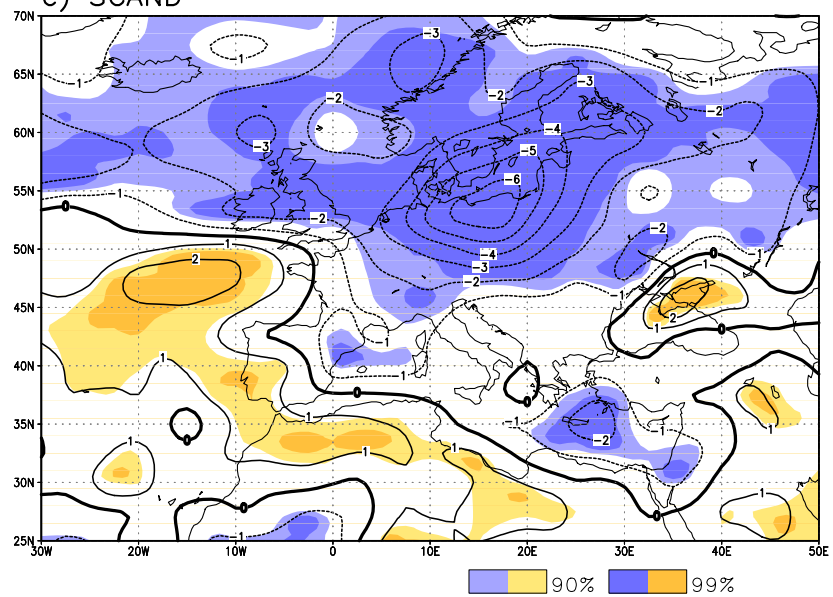

Fig. 10. Wind track density difference between positive and negative phase of large-scale pattern. Calculated for extended winter season. (a) NAO (b) East-Atlantic West-Russian pattern (c) Scandinavian pattern. Shaded are $90 \%$ and $99 \%$ significance levels. Contour lines denote change in number of cyclones per extended winter season (ONDJFM) per (deg.lat.) ${ }^{2}$. 


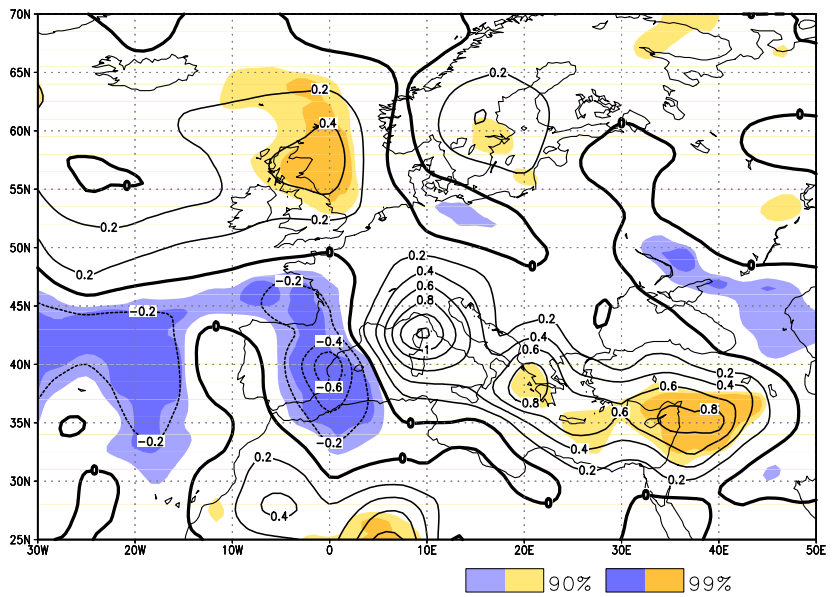

Fig. 11. Difference in cyclogenesis between positive and negative phase of the NAO for cyclones associated with wind events in the Mediterranean region. Calculated for extended winter season. Shaded are $90 \%$ and $99 \%$ significance levels. Contour lines denote change in number of events per extended winter season (ONDJFM) per (deg.lat.) $)^{2}$.

pattern. As has been pointed out by Bengtsson et al. (2004), the lack of satellite observations prior to 1979 can influence the results obtained using reanalyses in climate studies. We have repeated the analysis using only the years after 1979 and found that the spatial distribution of the signal, showing the influence of the teleconnection patterns on extreme wind tracks, remains stable for all three patterns. In fact, the absolute values of the signal for the eastern MR are slightly stronger for the period after 1979.

This study has quantified the spatial differences between the location of the cyclone cores and the associated extreme wind tracks. Two factors contribute to the differences: the area of impact associated with the cyclone is not identical to the position of its core. In addition, the wind producing cyclones do not generate high winds during their entire life cycle. Both effects have to be taken into account in the interpretation of cyclone tracks and their changes in Greenhouse Gas Scenario studies (e.g. Muskulus and Jacob, 2005; Lionello et al., 2008; Raible et al., 2009). The spatial differences are especially noticeable when analysing the effect of the NAO teleconnection pattern on the number of extreme wind producing cyclones and wind tracks in the eastern MR. The number of extreme wind tracks significantly increases over the whole eastern Mediterranean basin during the positive phase of the NAO. For the number of extreme wind producing cyclones, the significant increase during NAO+ is restricted to the Levant region as two opposing effects contribute to the signal: the number of cyclones entering from the western MR is reduced during $\mathrm{NAO}+$, while at the same time there is an increase in cyclogenesis of wind producing cyclones over the eastern MR.
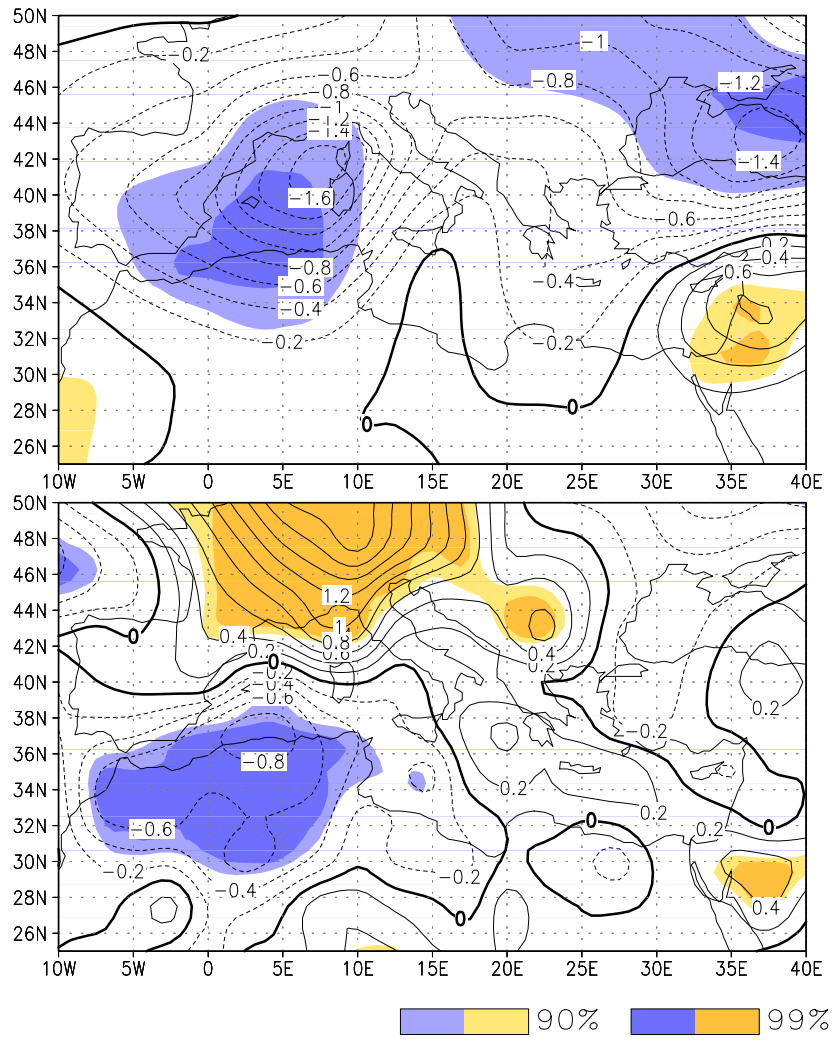

Fig. 12. Top: linear trend of cyclone track density in number of winter cyclones per decade per (deg.lat.) $)^{2}$ for all cyclones. Bottom: linear trend of wind track density. Shaded are $95 \%$ and $99 \%$ significance levels.

Ben-Gai et al. (2001) analysed the relationship between NAO, SLP and geopotential height fields over Israel in winter. During the positive phase of the NAO, they found higher SLP values over Israel. At first sight, this appears to be in conflict with the increase in the number of cyclones over the Levant region reported here. Analysis of the ERA40 dataset shows that the MSLP field exhibits higher pressure values throughout the MR (including Israel) during NAO+ than during NAO-. Due to the higher background surface pressure, the cyclones crossing over the Levant region during the positive phase of the NAO tend to have shallower core pressures than the cyclones during NAO-. On the other hand, they feature higher values of $\nabla^{2} p$, which is consistent with the higher number of extreme wind tracks. The cyclones occurring during $\mathrm{NAO}+$ tend to remain longer within the Levant region. The mean ERA40 $500 \mathrm{hPa}$ height field features a slight wave-like disturbance over south-eastern Europe during $\mathrm{NAO}+$, resulting in lower $500 \mathrm{hPa}$ height levels over the eastern MR. The situation suggests a more frequent occurrence of upper-level troughs in the vicinity. 
We have compiled composites of MSLP and $500 \mathrm{hPa}$ geopotential height for the days prior to cyclogenesis of extreme wind producing cyclones during NAO+ in selected regions. For the Cyprus and Levant region the composites reveal a low surface pressure anomaly in the vicinity of the Red Sea extending northwards, which is accompanied by a pronounced trough at the $500 \mathrm{hPa}$ level over the eastern MR. The cyclogenesis south of Greece is associated with a negative MSLP anomaly extending from higher latitudes, which is again accompanied by a $500 \mathrm{hPa}$ trough. The existence of an upper-level trough implies the intrusion of cold air from high latitudes leading to instability and cyclogenesis.

The importance of atmospheric large-scale variability for the number and spatial distribution of Mediterranean extreme wind events is further emphasized when analysing the linear trend in the number of wind events and the wind inducing cyclones. There is evidence that a third of the trends detected for the winter season of the 45-year ERA40 period may be associated with the variability of the NAO, which exhibited a strong positive period during the 1980s and 1990s. This positive period during the second half of the time series results in a significant decrease in the number of cyclones and wind events in the western MR and an increase at the southeastern Mediterranean shore. The sign and spatial distribution of the trend is consistent with the changes found for the influence of the NAO on wind storms and storm inducing cyclones.

The strong role of the NAO on Mediterranean climate variability has been reported previously by Lionello and Sanna (2005), who found an anti-correlation of winter significant wave height in the Mediterranean region and the NAO. On the other hand, Pirazzoli and Tomasin (2003) did not find a significant correlation between near surface winds in the central Mediterranean and the NAO analysing annual data for the second half of the 20th century. This suggests that the influence of the NAO on the MR depends on the season, as recently documented for the Northeast Atlantic region by Wang et al. (2009).

In a next step, we will analyse the impact of climate change to cyclone activity and the occurrence of wind storms within the MR. The role of the large-scale patterns under future climate conditions will also be investigated.

Acknowledgements. This work was funded by the EU integrated project Climate Change and Impact Research: the Mediterranean Environment (CIRCE), project no. 036961. We thank the two reviewers for their valuable comments, which helped to improve the manuscript.

Edited by: R. García-Herrera

Reviewed by: two anonymous referees

\section{References}

Alpert, P., Neeman, B. U., and Shay-El, Y.: Climatological analysis of Mediterranean cyclones using ECMWF data, Tellus A, 42, 65-77, 1990.

Alpert, P., Osetinsky, I., Ziv, B., and Shafir, H.: Semi-objective classification for daily synoptic systems: Application to the Eastern Mediterranean climate change, Int. J. Climatol., 24, 1001-1011, doi:10.1002/joc.1036, 2004.

Barnston, A. G. and Livezey, R. E.: Classification, seasonality and persistence of low-frequency atmospheric circulation patterns, Mon. Weather Rev., 115, 1083-1126, 1987.

Ben-Gai, T., Bitan, A., Alpert, P., and Kushnir, Y.: Temperature and surface pressure anomalies in Israel and the North Atlantic Oscillation, Theor. Appl. Climatol., 69, 171-177, 2001.

Bengtsson, L., Hodges, K. I., and Hagemann, S.: Sensitivity of the ERA40 reanalysis to the observing system: determination of the global atmospheric circulation from reduced observations, Tellus A, 56, 456-471, 2004.

Blender, R. and Schubert, M.: Cyclone Tracking in Different Spatial and Temporal Resolutions, Mon. Weather Rev., 128, 377348, 2000.

Blender, R., Fraedrich, K., and Lunkeit, F.: Identification of cyclone-track regimes in the North Atlantic, Q. J. Roy. Meteorol. Soc., 123, 727-741, 1997.

Hodges, K. I.: Feature Tracking on the Unit Sphere, Mon. Weather Rev., 123, 3458-3465, 1995.

Homar, V., Jansà, A., Campins, J., Genovés, A., and Ramis, C.: Towards a systematic climatology of sensitivities of Mediterranean high impact weather: a contribution based on intense cyclones, Nat. Hazards Earth Syst. Sci., 7, 445-454, doi:10.5194/nhess-7445-2007, 2007.

Hurrell, J. W. and van Loon, H.: Decadal variations in climate associated with the north Atlantic oscillation, Climatic Change, 36, 301-326, 1997.

Krichak, S. O. and Alpert, P.: Signatures of the NAO in the atmospheric circulation during wet winter months over the Mediterranean region, Theor. Appl. Climatol., 82, 27-39, 2005a.

Krichak, S. O. and Alpert, P.: Decadal trends in the East-Atlantic West Russia pattern and the Mediterranean precipitation, Int. J. Climatol., 25, 183-192, 2005b.

Krichak, S. O., Tsidulko, M., and Alpert, P.: Monthly synoptic patterns associated with wet/dry conditions in the eastern Mediterranean, Theor. Appl. Climatol., 65, 215-229, 2000.

Krichak, S. O., Kishcha, P., and Alpert, P.: Decadal trends of main Eurasian oscillations and the Mediterranean precipitation, Theor. Appl. Climatol., 72, 209-220, 2002.

Krichak, S. O., Alpert, P., and Dayan, M.: Role of atmospheric processes associated with hurricane Olga in December 2001 floods in Israel, J. Hydrometeorol., 5, 1259-1270, 2004.

Leckebusch, G. C., Renggli, D., and Ulbrich, U.: Development and Application of an Objective Storm Severity Measure for the Northeast Atlantic Region, Meteorol. Z., 17, 575-587, 2008.

Lionello, P. and Sanna, A.: Mediterranean wave climate variability and its links with NAO and Indian Monsoon, Clim. Dynam., 25, 611-623, doi:10.1007/s00382-005-0025-4, 2005.

Lionello, P., Bhend, J., Buzzi, A., Della-Marta, P. M., Krichak, S. O., Jansà, A., Maheras, P., Sanna, A., Trigo, I. F., and Trigo, R.: Mediterranean Climate Variability, chap. Cyclones in the Mediterranean region: climatology and effects on the 
environment, Elsevier, Amsterdam, 325-372, 2006.

Lionello, P., Boldrin, U., and Giorgi, F.: Future changes in cyclone climatology over Europe as inferred from a regional climate simulation, Clim. Dynam., 30(6), 657-671, doi:10.1007/ s00382-007-0315-0, 2008.

Maheras, P., Flocas, H., Patrikas, I., and Anagnostopoulou, C.: A 40 year objective climatology of surface cyclones in the Mediterranean region: spatial and temporal distribution, Int. J. Climatol., 109-130, doi:10.1002/joc.599, 2001.

Murray, R. J. and Simmonds, I.: A numerical scheme for tracking cyclone centres from digital data. Part I: development and operation of the scheme, Aust. Meteorol. Mag., 39, 155-166, 1991.

Muskulus, M. and Jacob, D.: Tracking cyclones in regional model data: the future of Mediterranean storms, Adv. Geosci., 2, 13-19, doi:10.5194/adgeo-2-13-2005, 2005.

Palmieri, S., Siani, A., and D'Agostino, A.: Climate fluctuations and trends in Italy within the last 100 years, Ann. Geophys., 9, 769-776, 1991 http://www.ann-geophys.net/9/769/1991/.

Pinto, J. G., Spangehl, T., Ulbrich, U., and Speth, P.: Sensitivities of a cyclone detection and tracking algorithm: individual tracks and climatology, Meteorol. Z., 14, 823-838, 2005.

Pinto, J. G., Fröhlich, E. L., Leckebusch, G. C., and Ulbrich, U.: Changing European storm loss potentials under modified climate conditions according to ensemble simulations of the ECHAM5/MPI-OM1 GCM, Nat. Hazards Earth Syst. Sci., 7, 165-175, doi:10.5194/nhess-7-165-2007, 2007.

Pinto, J. G., Zacharias, S., Fink, A. H., Leckebusch, G. C., and Ulbrich, U.: Factors contributing to the development of extreme North Atlantic cyclones and their relationship with the NAO, Clim. Dynam., 32, 711-737, doi:10.1007/s00382-008-0396-4, 2009.

Pirazzoli, P. A. and Tomasin, A.: Recent near-surface wind changes in the central Mediterranean and Adriatic areas, Int. J. Climatol., 23, 963-973, doi:10.1002/joc.925, 2003.

Radinovic, D.: Mediterranean cyclones and their influence on the weather and climate, WMO PSMP Rep., Ser. Num 24, 1987.

Raible, C. C.: On the relation between extremes of midlatitude cyclones and the atmospheric circulation using ERA40, Geophys. Res. Lett., 34, L07703, doi:10.1029/2006GL029084, 2007.

Raible, C. C., Yoshimori, M., Stocker, T. F., and Casty, C.: Extreme midlatitude cyclones and their implications for precipitation and wind speed extremes in simulations of the Maunder Minimum versus present day conditions, Clim. Dynam., 28, 409-423, doi: 10.1007/s00382-006-0188-7, 2006.

Raible, C. C., Saaroni, H., Ziv, B., and Wild, M.: Winter cyclonic activity over the Mediterranean Basin under future climate based on the ECHAM5 GCM, Clim. Dynam., in press, doi:10.1007/ s00382-009-0678-5, 2009.
Serezze, M. C., Carse, F., Barry, R. G., and Rogers, J. C.: Icelandic Low Cyclone Activity: Climatological Features and Linkages with the NAO, and Relationship with Recent Changes in Northern Hemispheric Circulation, J. Climate, 10, 453-464, 1997.

Trigo, I. F.: Climatology and interannual variability of storm-tracks in the Euro-Atlantic sector: a comparison between ERA-40 and NCEP/NCAR reanalyses, Clim. Dynam., 26, 127-143, doi:10. 1007/s00382-005-0065-9, 2005.

Trigo, I. F. and Davies, T. D.: Meteorological conditions associated with sea surges in Venice: a 40 year climatology, Int. J. Climatol., 22, 787-803, 2002.

Trigo, I. F., Davies, T. D., and Bigg, G. R.: Objective climatology of cyclones in the Mediterranean region, J. Climate, 12, 16851696, 1999.

Trigo, I. F., Davies, T. D., and Bigg, G. R.: Decline in Mediterranean rainfall caused by weakening of Mediterranean cyclones, Geophys. Res. Lett., 27, 2913-2916, 2000.

Trigo, R. M., Valente, M. A., Trigo, I. F., Miranda, P., Ramos, A. M., Paredes, D., and García-Herrera, R.: The Impact of North Atlantic Wind and Cyclone Trends on European Precipitation and Significant Wave Height in the Atlantic, Ann. N.Y. Acad. Sci., 1146, 212-234, 2008.

Ulbrich, U., Leckebusch, G. C., and Pinto, J. G.: Extra-tropical cyclones in the present and future climate: a review, Theor. Appl. Climatol., 96, 117-131, doi:10.1007/s00704-008-0083-8, 2009.

Uppala, S. M., Kållberg, P. W., Simmons, A. J., Andrae, U., Bechtold, V. D. C., Fiorino, M., Gibson, J. K., Haseler, J., Hernandez, A., Kelly, G. A., Li, X., Onogi, K., Saarinen, S., Sokka, N., Allan, R. P., Andersson, E., Arpe, K., Balmaseda, M. A., Beljaars, A. C. M., Berg, L. V. D., Bidlot, J., Bormann, N., Caires, S., Chevallier, F., Dethof, A., Dragosavac, M., Fisher, M., Fuentes, M., Hagemann, S., Hólm, E., Hoskins, B. J., Isaksen, L., Janssen, P. A. E. M., Jenne, R., Mcnally, A., Mahfouf, J.-F., Morcrette, J.J., Rayner, N., Saunders, R. W., Simon, P., Sterl, A., Trenberth, K. E., Untch, A., Vasiljevic, D., Viterbo, P., and Woollen, J.: The ERA-40 re-analysis, Q. J. Roy. Meteor. Soc., 131, 2961-3012, 2005.

Wang, X. L., Zwiers, F. W., Swail, V. R., and Feng, Y.: Trends and variability of storminess in the Northeast Atlantic region, 1874-2007, Clim. Dynam., 33, 1179-1195, doi:10.1007/ s00382-008-0504-5, 2009.

Zolina, O. and Gulev, S. K.: Improving the Accuracy of Mapping Cyclone Numbers and Frequencies, Mon. Weather Rev., 130, 748-759, 2002. 